\title{
KAIN SEBAGE
}

\author{
Era Paraswati *)
}

\begin{abstract}
ABSTRACK
Sebage fabric is one of the typical fabric manufacturing techniques Lampung are made with batik techniques. Along with the development of batik in Indonesia. Fabric Sebage reintroduced in 1999 by Governor Drs. Oemarsono, at that time. Sebage fabric used for traditional ceremonial purposes. Sebage fabrics grouped into two types, namely Sebage fabric Balak (Large) and Sebage fabric Lunik (Small).
\end{abstract}

Keywords: Fabric, Sebage, Batik, Lampung

\begin{abstract}
ABSTRAK
Kain Sebage merupakan salah satu kain khas daerah Lampung yang teknik pembuatannya dibuat dengan teknik membatik. Seiring dengan perkembangan batik di Indonesia. Kain Sebage diperkenalkan kembali pada tahun 1999 oleh Gubernur Drs. Oemarsono, pada saat itu. Kain sebage digunakan untuk kepentingan upacara adat. Kain sebage dikelompokan menjadi 2 jenis yaitu kain sebage Balak (Besar) dan Kain Sebage Lunik (Kecil).
\end{abstract}

Kata Kunci: Kain, Sebage, Batik, Lampung

\section{PENDAHULUAN}

Dalam keanekaragaman kebudayaan Lampung terdapat warisan budaya tak benda yang disebut kain khas Lampung. Kain khas Lampung terdiri dari beberapa kain seperti, Sebage, Tapis, Bidak, Teppal, Selekap, Cindai, Peleppai dan Nampan (Musyawarah marga pada tanggal 25-27 Agustus 1998 di Bandar Lampung). Seiring dengan perkembangan batik di Indonesia, propinsi Lampung mulai memperkenalkan kain sebage, yang pembuatannya menggunakan teknik membatik. Untuk memiliki identitas batik sendiri, maka mulai dikembangkan batik khas Lampung. Kain sebage diperkenalkan pada tanggal 6 Maret 1999 dalam acara Pekan Seni Budaya Lampung ke-XIV yang diresmikan oleh Gubernur saat itu Drs.Oemarsono.

Kain sebage memiliki ragam fungsi dan kegunaan, seperti untuk acara adat, keagamaan, perkawinan, dan peringatan hari besar hingga digunakan untuk menutupi jenazah. Kain sebage memiliki corak dan warna yang mengandung makna

*Era Paraswati (bermaiiin.mind@gmail.com), Mahasiswa Pascasarjana ISI Yogyakarta 
simbolis yang menyiratkan nilai budaya Lampung. Motif dan corak warna kain sebage dipengaruhi oleh motif dan warna kain tekstil India. Dilihat dari sejarahnya Kain Sebage terdiri dari 12 motif, yaitu Sebage Sekebar, Sependendum, Belando, Suluh, Kembang Matahari, Kembang Cinou, Kembang Melur, Kembang Gugur, Kebang Kaco Piring, Kembang Gedian, Kembang Teleng dan Kembang Kaweng.

Perkembangan kain sebage sejak diresmikan kembali pada tahun 1999 hingga sekarang masih belum memperlihatkan hasilnya. Kurangnya informasi dan sumber buku tentang kain sebage mempengaruhi perkembangan kain sebage. Usaha pemerintah untuk memperkenalkan kain sebage melalui pameran kebudayaan belum membuahkan hasil.

Ragam motif kain Sebage sangat banyak, namun sampai sekarang Pemda Tingkat I Lampung melalui Dinas $\mathrm{P}$ dan $\mathrm{K}$ baru dapat menyiapkan duplikat dari 12 motif saja. Hal tersebut disebabkan kerena dalam dekade ini kain Sebage sulit didapati karena hanya dimiliki oleh orang-orang tertentu dan kain sebage tidak diproduksi lagi.

Berikut akan dibahas beberapa jenis dan motif kain Sebage serta bahan dan cara pembuatannya.

\section{PEMBAHASAN}

\section{Sejarah Kain Sebage}

Kain sebage adalah salah satu kain khas Lampung yang sudah dikenal dari abad 17M, kemudian pada abad 18- 19M yang ditandai kedatangan bangsa India dengan membawa kain bermotif bunga yang dikenal dengan kain chitz dan patola yang kemudian terjadi percampuran kebudayaan Lampung dengan India (Wijaya, 2012: 1). Seiring perkembangannya, kain sebage kemudian makin dikenal menjadi salah satu pakaian adat yang disakralkan oleh masyarakat adat yang tersebar di Lampung. Kain sebage memiliki ragam fungsi dan kegunaan, perkawinan, dan hari besar lainnya hingga digunakan untuk menutupi jenazah.

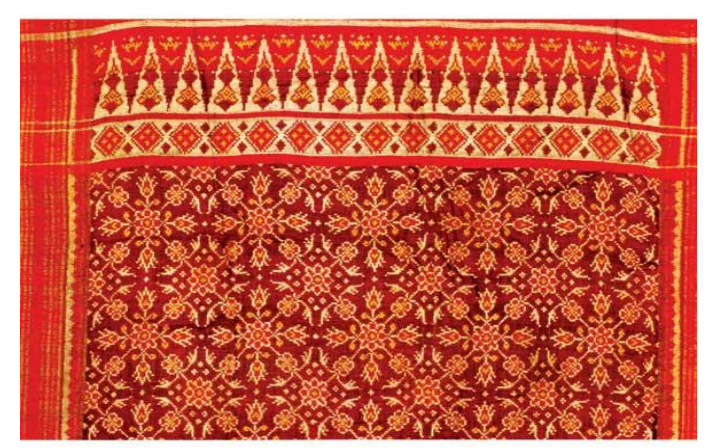

Gambar 1. Kain Patola dari India

(Sumber: http://www.fashionpromagazine.com)

Ada beberapa kain yang motifnya serupa dengan kain sebage:

1. Patola

Kain Patola yang berasal dari India, dan dibawa oleh pedagang dari India. Kain yang kemudian juga dibawa oleh pedagang bangsa Portugis ke Indonesia ini memiliki corak dasar yang umumnya berupa ragam hias yang menggambarkan manusia, binatang, tumbuhan dan susunan bentuk-bentuk geometris. Proses pembuatan kain Patola dilakukan dengan teknik tenun ikat ganda dan pembuatannya ini pun sangat rumit. Karena proses pembuatannya yang sangat rumit, kain ini mereka anggap sebagai kain keramat yang sering dikaitkan dengan dunia gaib. 
Di India kain ini sering digunakan dalam berbagai upacara yang berhubungan dengan daur kehidupan manusia, seperti kelahiran, perkawinan dan kematian. Selain itu kain inipun digunakan sebagai penolak bala. Keberadaan kain Patola tersebar luas di kepulauan Nusantara dan di setiap tempat kain ini menempati kedudukan yang sangat tinggi, bukan karena harganya yang sangat mahal tetapi karena daya magis yang dimilikinya.

2. Gringsing

Kain Gringsing adalah kain tradisional Bali yang mengandung nilai budaya dan nilai sejarah. Kain ini ditenun dengan menggunakan teknik ikat dobel dan memerlukan 2 sampai 5 tahun proses pembuatannya. Pembuatan kain ini dari awal hingga akhir dikerjakan dengan tangan tanpa menggunakan mesin. Benang yang dipakai adalah benang kapuk yang berasal dari Nusa Penida. Proses pewarnaan kain Gringsing menggunakan pewarna alami. Motif kain Gringsing cukup banyak, namun yang sering digunakan hanya 14 motif.

Menurut kepercayaan masyarakat bali, kain ini dapat digunakan untuk menolak bala atau menolak berbagai penyakit dan sering digunakan untuk upacara adat.

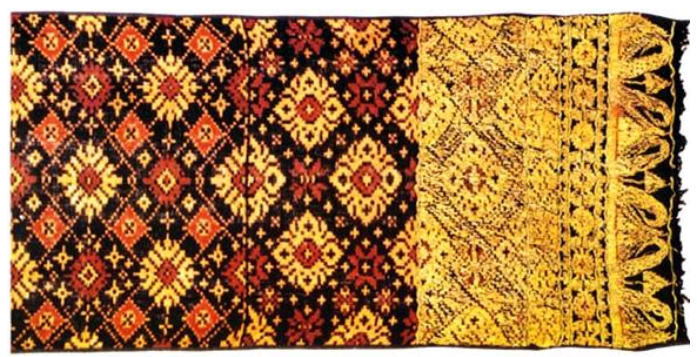

Gambar 2. Kain Gringsing dari Desa Tenganan Bali (Sumber: http://www.fashionpromagazine.com)

\section{Cinde/ Cindai}

Kain Cinde merupakan sebutan lain dari kain Patola di daerah Jawa, sedang di daerah Sumatra disebut Cindai.

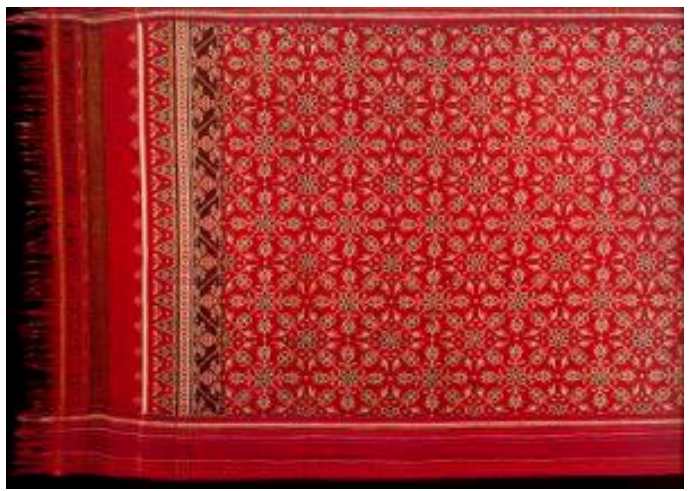

Gambar 3. Kain Cindai

(Sumber: https://tokuban78.wordpress.com)

\section{Sinde}

Dibagian timur Indonesia kain Patola disebut kain Sinde. Sebutan Sinde berasal dari Tchinde yang merupakan sebutan lain dari Kain Patola di India.

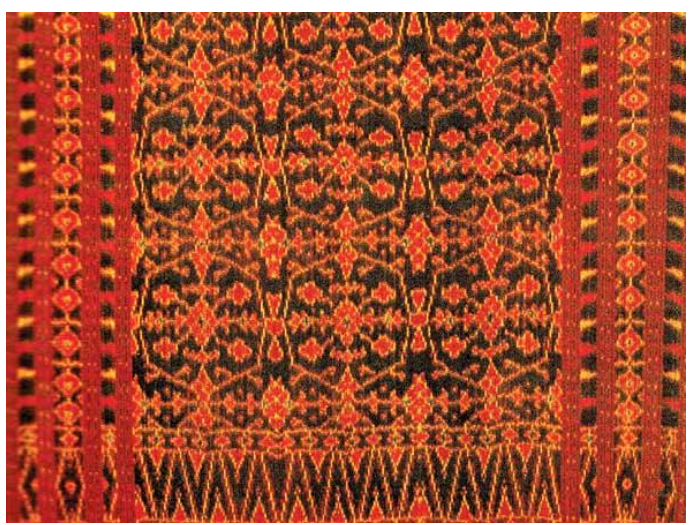

Gambar 4. Kain Sinde dari Lio Flores NTT

(Sumber: http://www.fashionpromagazine.com)

\section{Sembagi}

Kain Sembagi atau juga disebut Chintz (Kain dengan motif bunga) berasal dari pesisir Coromandel India (Sembagi) mulai muncul di Kerajaan Sriwijaya sekitar abad ke-VII. Ornamen hiasan tumbuhan 
pada kain Sembagi serasi pada masa itu dan mencerminkan tingkat sosial pemakainya. Hal ini tidak salah dikatakan bahwa perdagangan tekstil motif bunga atau Kain Sembagi menyebar di seluruh daerah Sumatera dan Jawa.

Kain Sembagi mulai ditiru oleh pengusaha batik Arab dan Cina kira-kira pada abad ke-XIX khususnya di daerah Cirebon dan Lasem, yang kemudian dikenal sebagai Batik Sembagi.

Batik Sembagi di Jawa dan Sumatera mengalami modifikasi motif. Di Sumatera khususnya Jambi, dihiasi dengan gaya motif yang diambil dari buah-buahan dan warnawarna Batik Sembagi hampir tidak menyentuh daerah asalnya.

Sembagi yang berwarna terang digunakan pada upacara mandi pengantin dan hiasan dinding pada upacara adat. Kain Sembagi yang berwarna gelap digunakan untuk penutup jenazah.

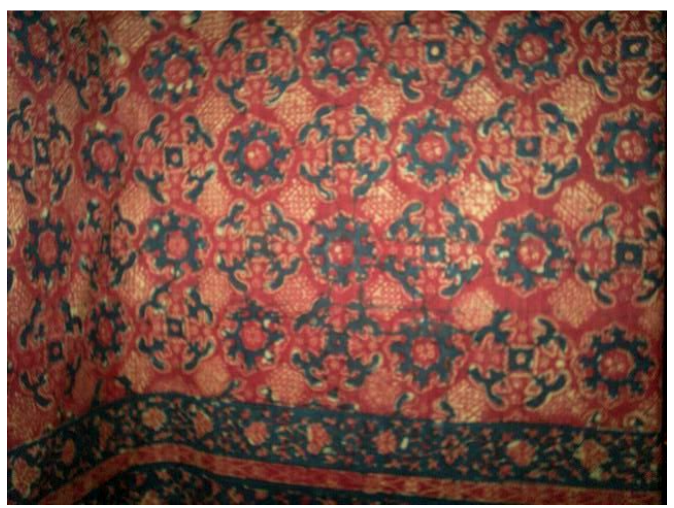

Gambar 5. Kain Sembagi

(Sumber:

http://museumbatikdanarhadi.blogspot.com)

6. Batik Motif Jelamprang dan Nitik

Motif jlamprang dan Nitik terbentuk dari lingkaran-lingkaran yang bersinggungan satu sama lain. Motif Patola memengaruhi motif batik Jlamprang yang berwarna cerah yang berkembang di Pekalongan, dan motif Nitik yang berkembang di Yogyakarta dan Surakarta yang berwarna sogan (kecokelatan), indigo (biru), kuning dan putih.

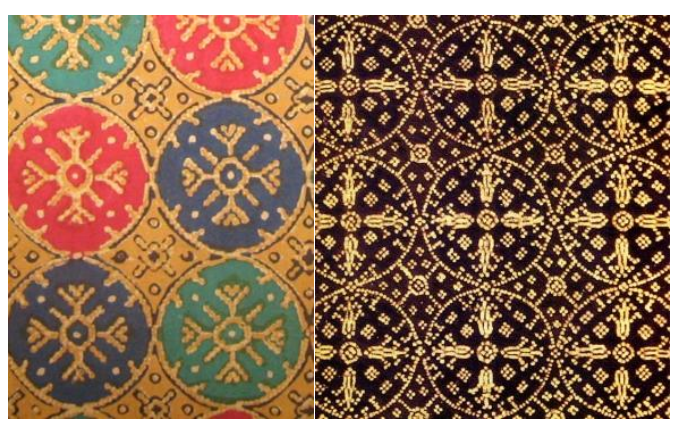

Gambar 6. Batik Motif Jelamprang dan Nitik (Sumber:

http://museumbatikdanarhadi.blogspot.com)

Beberapa jenis kain diatas termasuk kain Sebage, berkembang dan mengadaptasi kain Patola asal India yang dibawa oleh pedagang dari Gujarat. Kain Patola tersebar diwilayah indonesia melalui jalur perdagangan karena secara geografis Indonesia terletak pada persimpangan kebudayaan besar, yaitu antara benua Asia dan Australia. Hal tersebut mempengaruhi dan mengakibatkan terjadinya akulturasi budaya, yang salah satunya tampak pada kekayaan tekstil di Indonesia.

\section{Jenis Kain Sebage}

Kain sebage dibagi kedalam 2 jenis yaitu:

1. Sebage balak (besar)

Sebage balak umumnya digunakan untuk upacara-upacara ritual dan adat dengan klasifikasi pemakaiannya hanya pada orang-orang tertentu saja. Kain Sebage balak dibagi menjadi 5 motif sebagai berikut. 
a. Sebage Sekebar

Sebage Sekebar dipakai oleh bapak dan ibu pemuka adat pada waktu upacara adat seperti upacara Cakak Pepadun, Turun Diway, Serak Sepi dan Betammat.

b. Sebage Sependendum
Sebage ini dipakai oleh ibu-ibu pemuka adat tingkat penyimbang tuho dan penyimbang marga pada waktu upacara adat turun mandi dan cakak pepadun.

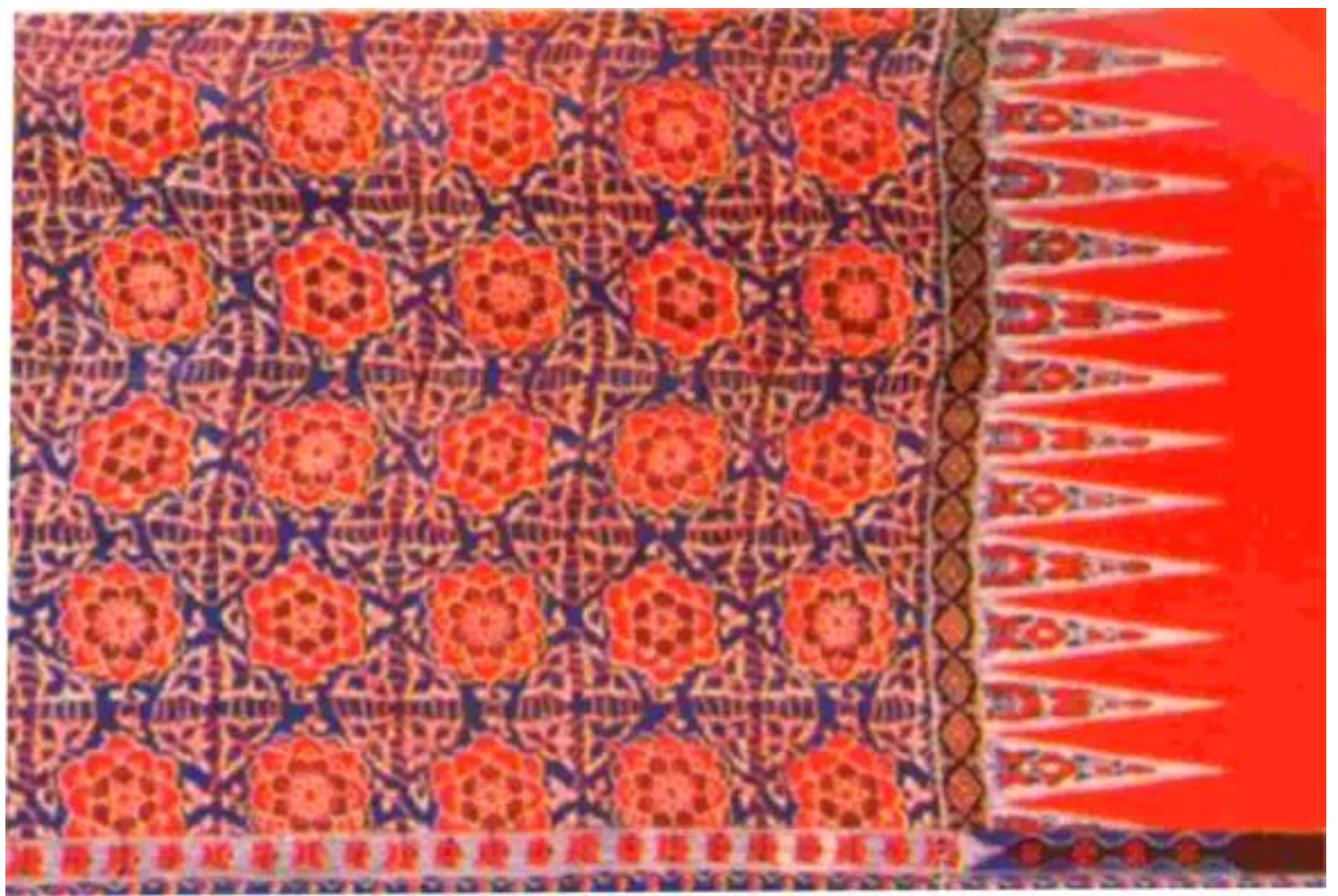

Gambar 7. Sebage Sependendum, (Sumber: Dinas P dan K Propinsi Lampung, 1999)

C. Sebage Belando

Sebage Belando dipakai oleh bapak pemuka adat tingkat penyimbang Tiuh pada waktu upacara adat cakak pepadun dan turun mandi.

d. Sebage Suluh

Sebage Suluh dipakai oleh bapak dan ibu pemuka adat tingkat penyimbang suku pada upacara adat cakak pepadun dan turun diway.

e. Sebage Kembang Matahari
Sebage kembang matahari khusus dipakai oleh penyimbang Tiuh untuk para ibu-ibu pada waktu upacara adat cakak pepadun dan turun diway.

2. Sebage lunik (kecil)

Sebage lunik adalah sebage yang digunakan secara umum oleh masyarakat untuk ritual dan adat dan digunakan dalam kehidupan sehari-hari bagi masyarakat umum yang mampu memilikinya. Sebage Lunik antara lain sebagai berikut. 
a. Sebage Kembang Cinou

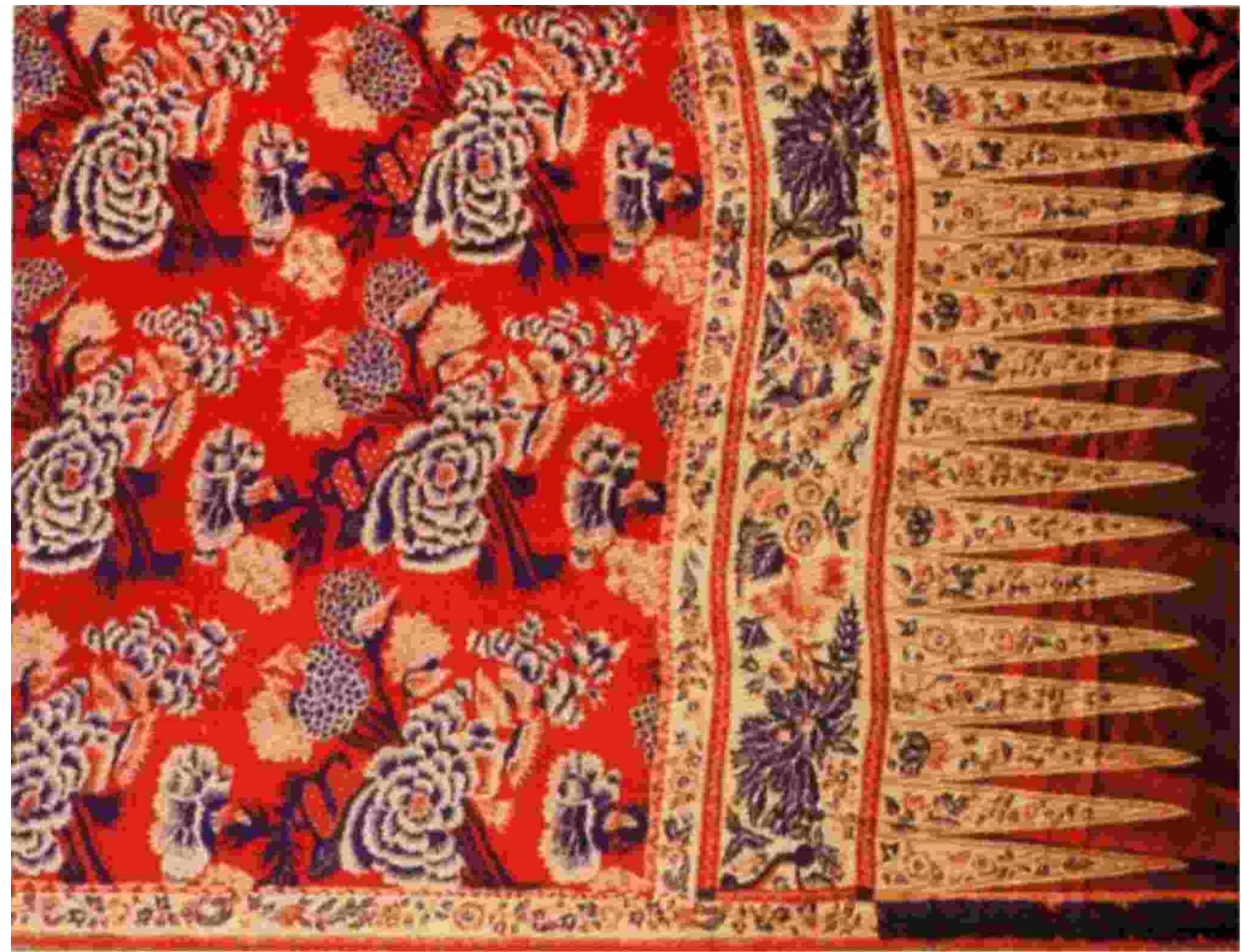

Gambar 8. Sebage Kembang Cinou, (Sumber: Dinas P dan K Propinsi Lampung, 1999)

b. Sebage Kembang Melur

c. Sebage Kembang Gugur

d. Sebage Kembang Kaco Piring

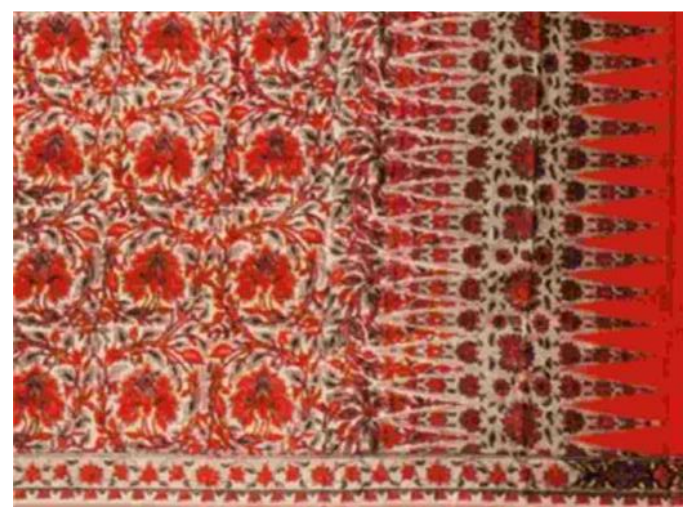

Gambar 9. Sebage Kembang Kaco Piring

(Sumber: Dinas P dan K Propinsi Lampung, 1999) e. Sebage Kembang Gedian

f. Sebage Kembang Teleng

g. Sebage Kembang Kaweng

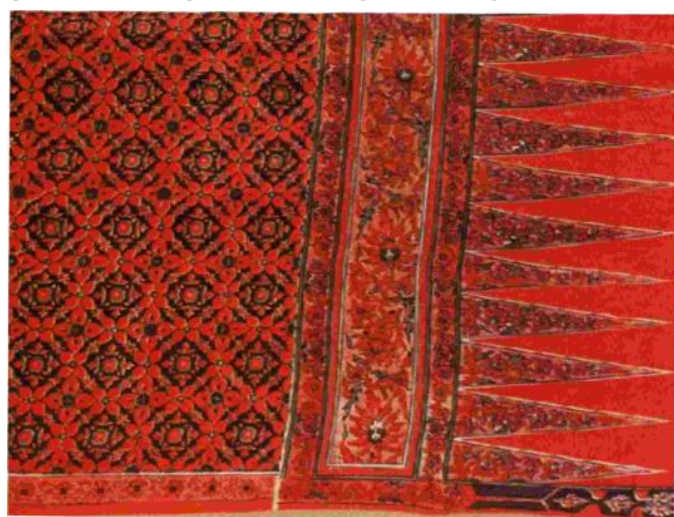

Gambar 10. Sebage Kembang Kaweng

(Sumber: Dinas P dan K Propinsi Lampung, 1999) 
PENUTUP

Motif Kain sebage mengadaptasi motif pada kain Patola yaitu berbentuk geometris. Sedangkan teknik pembuatannya berbeda. Proses pembuatan kain Sebage menggunakan teknik batik sedangkan kain Patola menggunakan teknik tenun dobel ikat.

Dalam penulisan artikel ini, penulis kesulitan untuk mencari sumber data dan informasi tentang kain sebage. Sumber yang ada belum cukup mampu menjalaskan secara detail mengenai kain sebage dan karekteristik teknik dan motifnya. Melalui tulisan singkat ini penulis harap akan ada peneliti dan seniman yang berminat meneliti dan mengembangkan serta menggali kain khas Sebage lebih lanjut.

\section{KEPUSTAKAAN}

Dinas P dan K Propinsi Lampung. 1999. Kain Khas Sebage. Badan Penerbit Dinas P dan K Propinsi Lampung.

Wijaya, Wijaya R.Dimas Yogi. 2012. Perancangan media informasi pengenalan kain sebagi untuk anak SMK N 3 Bandar Lampung. Perpustakaan UNIKOM.

http://www.fashionpromagazine.com (diakses pada: 4 Februari 2015 pukul 22.41 WIB)

https://tokuban78.wordpress.com (diakses pada: 5 Februari 2015 pukul 05.43 WIB) http://museumbatikdanarhadi.blogspot.co m (diakses pada: 4 Februari 2015 pukul 22.43 WIB) 